\title{
Study of the Vitamin D Levels in Patients Referred to Clinical Laboratories in Mashhad in 2015 and their Relationship with the Patients' Lipid Profiles
}

\author{
Ali Akbar Shamsian ${ }^{1}$, Seyyed Abdolrahim Rezaee ${ }^{2}$, Majid Rajabiian ${ }^{3}$, Habibolah Taghizadeh Moghaddam4, \\ Masumeh Saeidi ${ }^{5}$, Abbas Bahreini ${ }^{6}$
}

${ }^{1}$ Department of Medical Parasitology and Mycology, Ghaem Hospital, Mashhad University of Medical Sciences, Mashhad, Iran

${ }^{2}$ Department of Immunology, Ghaem Hospital, Mashhad University of Medical Sciences, Mashhad, Iran

${ }^{3}$ Director of Biology Department, Payame Noor University, Tehran, Iran

${ }^{4}$ Department of Biochemistry, Ghaem Hospital, Mashhad University of Medical Sciences, Mashhad, Iran

${ }^{5}$ Students Research Committee, Faculty of Medicine, Mashhad University of Medical Sciences, Mashhad, Iran

${ }^{6}$ Department of Neurosurgery, Shiraz University of Medical Sciences, Shiraz, Iran

\section{Type of article: Original}

\begin{abstract}
Introduction: Vitamin D is a steroid hormone that has a significant role in the metabolism of minerals, especially calcium and phosphorus; it also is a major determinant of the strength of bones. This hormone has a significant effect on three major health issues that people worldwide encounter, i.e., high blood pressure, cancer, and diabetes. Considering the limited and dispersed studies on the prevalence of vitamin D deficiency in Iran and the relationship of vitamin D with lipid profiles in different people, this study was conducted to determine the vitamin D levels in patients and its relationship with their lipid profiles.

Methods: A retrospective cross-sectional study was conducted in 2015 on 1,110 patients who were referred to the two laboratories at Jihad Daneshgahi and to eight specialist laboratories in Mashhad through random sampling of patients for whom serum vitamin D and serum lipid tests were prescribed. The data that were obtained were entered into SPSS 13 software.

Results: Sixty-eight percent of the patients in the study were deficient in vitamin D. The vitamin D levels in males were significantly lower than those in females $(p<0.05)$. The relationship between age and vitamin $D$ deficiency was significant as well $(\mathrm{p}<0.05)$. A positive and significant relationship was observed between age and vitamin $\mathrm{D}$ deficiency $(\mathrm{p}=0.000, \mathrm{r}=0.187)$, i.e., vitamin $\mathrm{D}$ deficiency was more apparent in patients whose ages were in the range of 40-59. The relationship between the levels of vitamin D and serum lipids was significant and positive $(\mathrm{p}=0.05)$, with the exception of LDL.

Conclusion: About two-thirds of the population that was studied had a vitamin D deficiency. There was a positive and significant relationship between serum vitamin $\mathrm{D}$ and serum lipids and serum calcium. The results of this study showed the necessity for more research and the implementation of preventive measures related to vitamin D deficiency. It is recommended that vitamin D enrichment programs be planned and implemented.
\end{abstract}

Keywords: vitamin D; biochemical factors; laboratory; Mashhad; lipid profile

\section{Introduction}

Vitamin D deficiency is a common and serious problem worldwide, and this problem has an unusually high prevalence in sunny countries, such as those in the Middle East $(1,2)$. Vitamin D is a steroid hormone that helps facilitate the metabolism of minerals, especially calcium, and it is essential for strong bones. This vitamin possesses receptors in most organs of the body, including the pancreas, stomach, genitals, brain, and skin (3-5). Severe vitamin $\mathrm{D}$ deficiency can result in several disorders, including the mineralization of bones, rickets in children and adults, along with osteoporosis and pathologic fractures in adults (6-8). In addition to being obtained through skin

\section{Corresponding author:}

Habibolah Taghizadeh Moghaddam, Department of Biochemistry, Ghaem Hospital, Mashhad University of Medical Sciences, Mashhad, Iran. E-mail: TaghizadeMH1@mums.ac.ir

Received: July 02, 2015, Accepted: January 28, 2016, Published: April 2016

iThenticate screening: August 11, 2015, English editing: February 26, 2016, Quality control: March 28, 2016

(C) 2016 The Authors. This is an open access article under the terms of the Creative Commons Attribution-NonCommercialNoDerivs License, which permits use and distribution in any medium, provided the original work is properly cited, the use is non-commercial and no modifications or adaptations are made. 
synthesis, vitamin D can be absorbed through sunlight, which has the major role in supplying the required vitamin D. Thus, if this mechanism provides sufficient vitamin D, the need to acquire it through one's diet would be alleviated. Different factors affect the skin's synthesis of vitamin D due to exposure to sunlight, such as the distance from the Earth to the sun in different seasons, air pollution, the climate in the area, exposure to sunlight, and the type of clothing (9-11). The results of various studies have shown that about one billion people worldwide have severe or medium vitamin D deficiency $(7,12-14)$. With a half-life of two to three weeks, total serum $25(\mathrm{OH})$ vitamin D levels are considered to be the best index to determine people's vitamin D deficiency. Thus, measuring the levels of 25- $(\mathrm{OH})$ vitamin D could assist in diagnosing vitamin D deficiencies (15-17). In a study conducted in Yazd, severe vitamin D deficiency was reported in $53.7 \%$ of the participants, with $23.2 \%$ and $14.6 \%$ having medium and mild deficiencies, respectively (18). In another study conducted in Tehran in 2004, the prevalence of severe, medium, and mild vitamin D deficiency was reported as $9.5,57.6$ and $14.2 \%$ respectively (19). Another study of vitamin D deficiency was conducted in the urban populations of Tehran, Tabriz, Bushehr, Shiraz, and Mashhad among three age groups, i.e., people younger than 50, people in the age range of 50 to 60 , and people older than 60 . The results of the study indicated that, in the three age groups, medium to severe vitamin D deficiencies existed in 47.2, 45.7, and $44.2 \%$ of the males, respectively, and in $54.2,41.2$, and $37.5 \%$ of the females, respectively. According to the results of this study, the highest prevalence of medium to severe vitamin D deficiency was in males in Tehran, and the lowest prevalence was in females and males in Mashhad and Bushehr (20). Previous studies in Iran have shown significant vitamin D deficiencies in different groups. However, with regard to the high prevalence of vitamin D deficiency in Iran, it is essential to recognize the factors that affect this deficiency and to identify suitable strategies to overcome this problem. To that end, this study was conducted to investigate vitamin D levels and their relationship with the lipid profiles of patients who were referred to clinical laboratories in different districts of Mashhad. The results of this study could provide useful information for planning and conducting additional studies vitamin D deficiency in Iran.

\section{Material and Methods}

\subsection{Research design and setting}

This retrospective cross-sectional study was conducted in 2015, and it included 1,110 patients who were referred to 10 laboratories in Mashhad for diagnoses, i.e., two laboratories in Jihad Daneshgahi and eight others in different districts. Laboratories were chosen that were dispersed throughout the city, such that a laboratory was selected in each of the 10 districts of Mashhad. The sample size consisted of all patients who were referred to laboratories for vitamin $\mathrm{D}$ and other tests for blood biochemical factors.

\subsection{Data collection and analysis}

By obtaining an introduction letter from Payame Noor University of Mashhad (PUNM), the authors were referred to the laboratories to implement the plan. To collect the data, the required coordination was arranged by the Treatment Deputy of Mashhad University of Medical Sciences and the Head of Jihad Daneshgahi. Then, the lab officials were asked to present details of the patients (except their names) and the results of their tests. Specialists in laboratory sciences interpreted the results of the laboratory tests, and the authors assessed and analyzed the results of their interpretations. In this study, serum vitamin D levels of the patients were classified in four categories, i.e., vitamin D deficiency, insufficient amount of vitamin D, sufficient amount of vitamin $\mathrm{D}$, and toxic amount of vitamin $\mathrm{D}$ (19 and 21), as defined below:

1) Vitamin $D$ level $<20 \mathrm{ng} / \mathrm{ml}$ : vitamin $\mathrm{D}$ deficiency

2) Vitamin $D$ level $=20-30 \mathrm{ng} / \mathrm{ml}$ : insufficient amount of vitamin $D$

3) Vitamin D level $=30-100 \mathrm{ng} / \mathrm{ml}$ : sufficient amount of vitamin $\mathrm{D}$

4) Vitamin D level $>100 \mathrm{ng} / \mathrm{ml}$ : toxic amount of vitamin $D$

The raw data were entered into SPSS 13 software (SPSS Inc. Chicago, Illinois, USA), and they were analyzed using the Spearman rank correlation, ANOVA, and t-test. $\mathrm{P}<0.05$ was considered as significant.

\subsection{Research ethics}

The Research Ethics Committee of Mashhad University of Medical Sciences approved this study. The Deputy of Education of the University issued an introduction letter that allowed the researchers to enter the study area. In this study, it was not necessary to mention patients' names, and their details were extracted and used generally.

\section{Results}

We investigated the test results of 1,110 patients who were referred to diagnosis laboratories in Mashhad in 2015. The patients were 848 females $(76.4 \%)$ and 262 males $(23.6 \%)$. The patients in the study were divided into four 
categories based on their ages, i.e., 1) younger than 20 (5.9\%); 2) between 20 and 39 (28.8\%); 3) between 40 and 59 (45.5\%); and 60 and over (19.7\%). The results showed that $68.8 \%$ were vitamin D deficient, $14.6 \%$ had unsuitable levels of vitamin $\mathrm{D}, 0.5 \%$ had toxic levels of vitamin $\mathrm{D}$, and only $16.7 \%$ had suitable vitamin $\mathrm{D}$ levels. For the 1,110 patients in the study, Table 1 shows their mean serum levels of vitamin D, cholesterol, triglycerides, calcium, Highdensity lipoproteins (HDL), and Low-density lipoprotein (LDL) by gender. The data in Table 1 indicate that serum cholesterol and vitamin D levels were higher than normal in females. For males, the serum triglyceride level exceeded the recommended limit. LDL ('bad cholesterol') levels in females exceeded the recommended limit as well. The t-test showed a significant relationship between gender and HDL, LDL, Total cholesterol (TC), Triglyceride (TG) and vitamin D in the patients $(\mathrm{p}<0.05)$. No significant relationship was observed between calcium level and gender $(\mathrm{p}>0.05)$ (Table 1). The relationships between vitamin $\mathrm{D}$ and lipid profile by gender are shown in Table 2. The results showed that, in females, there was a significant relationship between vitamin $\mathrm{D}$ and cholesterol, triglycerides, HDL, and calcium, but there was no significant relationship between vitamin D and LDL. In addition, the results showed that there was no significant relationship between vitamin $\mathrm{D}$ and the calcium and lipid profiles $(p>0.05)$. The results showed that the age ranges of the patients in the study were 2-90 for males and 4-85 for females. The Spearman test was used to investigate the relationship between age and biochemical factors in the patients in the study, and the results showed a positive and significant relationship between age, vitamin $\mathrm{D}$, and calcium (Table 3). The ANOVA test showed that there was a significant mean difference between age and the biochemical factors $(p<0.05)$, except for calcium. In addition, the Tukey follow-up test showed that the difference between the means of the serum lipid profiles and age was significant $(p<0.05)$.

Table 1. Mean and standard deviation of biochemical indices in the patients by gender

\begin{tabular}{|l|l|l|l|}
\hline \multirow{2}{*}{ Variables } & \multicolumn{2}{|l|}{ Gender $($ Mean \pm SD) } & \multirow{2}{*}{-value } \\
\cline { 2 - 3 } & Female & Male & \\
\hline LDL $(\mathrm{gr} / \mathrm{dl})$ & $116.50 \pm 31.318$ & $123.26 \pm 30.758$ & 0.002 \\
\hline HDL $(\mathrm{gr} / \mathrm{dl})$ & $49.02 \pm 16.675$ & $52.09 \pm 16.365$ & 0.008 \\
\hline $\mathrm{TC}(\mathrm{gr} / \mathrm{dl})$ & $194.76 \pm 43.465$ & $202.13 \pm 42.832$ & 0.016 \\
\hline $\mathrm{TG}(\mathrm{gr} / \mathrm{dl})$ & $153.12 \pm 117.540$ & $136.18 \pm 86.599$ & 0.031 \\
\hline Calcium $(\mathrm{gr} / \mathrm{dl})$ & $9.504 \pm 0.6043$ & $9.492 \pm 3.2082$ & 0.953 \\
\hline Vitamin D $(\mathrm{gr} / \mathrm{dl})$ & $13.384 \pm 13.3331$ & $18.475 \pm 19.0097$ & 0.000 \\
\hline
\end{tabular}

Table 2. Relationship of vitamin D levels with biochemical factors in the patients by gender

\begin{tabular}{|l|l|l|l|l|}
\hline \multirow{2}{*}{ Biochemical factors } & \multicolumn{3}{l|}{ Male } & Female \\
\cline { 2 - 5 } & Spearman & $\mathrm{p}$-value & Spearman & $\mathrm{p}$-value \\
\hline TC & -0.006 & 0.917 & 0.070 & $0.040^{*}$ \\
\hline TG & -0.045 & 0.466 & 0.115 & $0.001^{*}$ \\
\hline LDL & -0.021 & 0.739 & 0.001 & 0.982 \\
\hline HDL & 0.083 & 0.179 & 0.100 & $0.004^{*}$ \\
\hline Calcium & 0.098 & 0.113 & 0.119 & $0.001^{*}$ \\
\hline
\end{tabular}

Table 3. Relationship between serum vitamin D levels and serum lipid profiles in the patients by age

\begin{tabular}{|c|c|c|c|c|c|c|c|c|}
\hline \multirow[t]{3}{*}{ Lipid profile } & \multicolumn{8}{|c|}{ Age group (year) } \\
\hline & \multicolumn{2}{|c|}{$<20$} & \multicolumn{2}{|l|}{$20-39$} & \multicolumn{2}{|l|}{$40-59$} & \multicolumn{2}{|l|}{$\geq 60$} \\
\hline & Spearman & $\mathrm{p}$-value & Spearman & p-value & Spearman & $\mathrm{p}$-value & Spearman & $\mathrm{p}$-value \\
\hline $\mathrm{TC}$ & -0.068 & 0.589 & -0.089 & 0.113 & -0.017 & 0.705 & -0.007 & 0.918 \\
\hline TG & -0.148 & 0.235 & 0.015 & 0.786 & -0.073 & 0.103 & -0.006 & 0.926 \\
\hline LDL & -0.046 & 0.711 & -0.093 & 0.097 & 0.003 & 0.941 & -0.032 & 0.637 \\
\hline HDL & -0.005 & 0.970 & -0.048 & 0.396 & 0.031 & 0.490 & 0.021 & 0.756 \\
\hline Calcium & 0.012 & 0.922 & 0.013 & 0.818 & 0.110 & $0.013 *$ & 0.132 & 0.051 \\
\hline
\end{tabular}

\section{Discussion}

The results of this study showed a high prevalence of vitamin D deficiency in the population that was studied. In all areas in the study, both genders had considerable vitamin D deficiencies, with about two-thirds of the population that was studied having vitamin D deficiencies and males showing a higher prevalence than females. Unfortunately, the amount of vitamin D absorbed in the body through nutritional sources is not sufficient. Foods enriched with vitamin D are limited, and they cannot supply the amounts of vitamin D required for children or adults. This issue 
could be the major cause of the epidemic prevalence of vitamin D deficiency even in European and American nations (21). In fact, the major source of the human body's supply of vitamin D is the vitamin D that is produced when the human body is exposed to the ultraviolet rays of the sun $(16,21)$. The results of various studies have shown that there is a higher prevalence of vitamin D deficiency in Middle East countries than in European and American countries $(1,7,10,13)$. It appears that regional customs concerning clothing are major factors that affect the prevalence of vitamin D deficiency in Middle East and Islamic countries, especially among women. Therefore, in nations in which women's clothing covers most parts of their bodies, such as Saudi Arabia, United Arab Emirates, Jordan, Turkey, and Lebanon, the prevalence of vitamin D deficiency is greater $(7,12,18)$. The results of this study were in good agreement with the results of Saeidnia's and Shakiba's studies $(12,18)$ in that all three studies showed a high prevalence of vitamin D deficiency in the patients that were studied. However, the results of this study did not confirm that the type of clothing had a significant effect on vitamin D deficiency, because this deficiency was found to be significantly greater in males than in females. In a study conducted in 2008 in Tehran, Shiraz, Tabriz, Mashhad, and Bushehr, a high prevalence of vitamin D deficiency was reported even in coastal areas and at low longitudes, where sun exposure is stronger and more direct. In this study, the major causes of the high prevalence of vitamin D deficiency was reported to be the lack of exposure to sunlight in spite of sufficient radiation in these areas (because of people's lifestyles), high pigmentation of the skin, and low nutritional intake of vitamin D and calcium (2).

In this study, a significant relationship was shown between vitamin D and amounts of serum lipids (HDL, cholesterol, and triglycerides) and calcium. This finding could represent the effectiveness of vitamin D with serum lipid profile in the body. Low calcium intake increases the catabolism of vitamin D. In previous studies, no apparent differences were identified between daily calcium intake and normal and low vitamin D levels (19). In this study, no significant decrease was observed in serum vitamin D levels with increasing age, as has been reported in other studies (23-25). There was a significant and direct relationship between age and vitamin $\mathrm{D}$ levels along with serum calcium and age of the patients, i.e., when the vitamin D levels were increased or decreased, the calcium levels were increased or decreased as well. Various studies of different age groups have produced different results of vitamin D deficiency, especially in elderly patients $(26,27)$.

\section{Conclusions}

The prevalence of vitamin D deficiency is high in Mashhad, and the prevalence is greater in men than in women. There was a direct and significant relationship between vitamin D and lipid profiles. A positive and significant relationship was observed between the decrease of vitamin D and the decrease of serum calcium, which may reflect the lack of dairy products consumed by the patients because of low economic status, poor nutrition, and lifestyle (avoiding exposure to sunlight). It appears that vitamin D deficiency is a common health issue in Mashhad that requires basic planning, especially to enrich food products with vitamin D and to increase peoples' awareness about this vitamin and the ways to increase its serum levels, especially in adults.

\section{Acknowledgments:}

The results presented in this study were derived from a thesis by Habibollah Taghi Zadeh Moghadam. The authors appreciate the assistance provided by the Deputy of Mashhad University of Medical Sciences and the technical officials of Jihad Daneshgahi laboratories of Mashhad that made it possible for us to conduct this study.

\section{Conflict of Interest:}

There is no conflict of interest to be declared.

Authors' contributions:

All authors contributed to this project and article equally. All authors read and approved the final manuscript.

\section{References:}

1) Michael F, Holick MF. Vitamin D deficiency: a worldwide problem with health consequences. Am J Clin Nutr. 2008;87(4):1080S-6S. PMID: 18400738.

2) Plehwe WE. Vitamin D deficiency in the 21 st century: an unnecessary pandemic? Clin Endocrinol (Oxf). 2003 Jul;59(1):22-4. PMID: 12807498.

3) Roth J, Bonner-Weir S, Norman AW, Orci L. Immunocytochemistry of vitamin D-dependent calcium binding protein in chick pancreas: exclusive localization. Endocrinology, 1982;110(6):2216-8. PMID: 7042327. 
4) Ettinger RA, Deluca HF. The vitamin D endocrine system and its therapeutic potential. Advances in Drug Research. 1996;28:269-312.

5) Aksens L. A simplified high-performance liquid chromatographic method for determination of vitamin D3, 25-hydroxyvitamin D2 and 25-hydroxyvitamin D3 in human serum. Scand J Clin Lab Invest. 1992 May;52(3):177-82. PMID: 1329183.

6) Brown AJ, Dusso A, Slatopolsky E. Vitamin D. Clin Calcium. 2002 Jun;12(6):711-23. PMID: 15775356.

7) Sullivan SS, Rosen CJ,Halteman WA, Chen TC, Holick MF. Adolescent girls in Maine are at risk for vitamin D insufficiency. J Am Diet Assoc. 2005;105(6):971-4. PMID: 15942551.

8) Holick MF. Vitamin D and bone health. J Nutr. 1996;126(4 Suppl):1159S-64S. PMID: 8642450.

9) Lagunova Z, Porojnicu AC, Aksnes L, Holick MF, Iani V, Bruland OS, Moan J. Effect of vitamin D supplementation and ultraviolet $\mathrm{B}$ exposure on serum 25-hydroxyvitamin D concentrations in healthy volunteers: a randomized, crossover clinical trial. $\mathrm{Br} \mathrm{J}$ Dermatol. 2013;169(2):434-40. doi: 10.1111/bjd.12349. PMID: 23551243.

10) Laurie Hickey, Catherine M. Gordon. Vitamin D deficiency: new perspectives on an old disease. Current Opinion in Endocrinology \&Diabetes. 2004;11(1):18-25. doi: 10.1046/j.1365-2265.2003.01800.x.

11) Hayes CE, Nashold FE, Spach KM, Pedersen LB. The immunological functions of the vitamin $D$ endocrine system. Cell Mol Biol (Noisy-le-grand). 2003 Mar;49(2):277-300. PMID: 12887108.

12) Saeidinia A, Larijani B, Jalalinia Sh, Farzadfar F, Keshtkar AA, Rezaei E, et al. Iranian Journal of Diabetes and Metabolism. 2014;12(6):574-84.

13) Lips P. Vitamin D status and nutrition in Europe and Asia. J Steroid Biochem Mol Biol. 2007 Mar;103(35):620-5. Epub 2007 Feb 6. PMID: 17287117.

14) DeLuca HF. Overview of general physiologic features and functions of vitamin D. Am J Clin Nutr. 2004 Dec;80(6 Suppl):1689S-96S. PMID: 15585789.

15) Rao LS, Ray R, Holick MF, Horst RL, Uskokovic MR, Reddy GS. Metabolism of [3alpha-3H] 25hydroxyvitamin D2 in kidneys isolated from normal and vitamin D2-intoxicated rats. J Nutr Sci Vitaminol (Tokyo). 2000 Oct;46(5):222-9. PMID: 11234914.

16) Schmidt-Gayk H, Bouillon R, Roth HJ. Measurement of vitamin D and its metabolites (calcidiol and calcitriol) and their clinical significance. Scand J Clin Lab Invest Suppl. 1997;227:35-45. PMID: 9127467.

17) Michael F, Holick M. Vitamin D deficiency. N Engl J Med. 2007; 357:266-81.

18) Shakiba M, Rafiei P. Prevalence of Vitamin D Deficiency Among Medical Staff in Shahid Sadoughi Hospital in Yazd, Iran. The journal of Toloo-e-behdasht. 2009;7(3): 22-30.

19) Hashemipour S, Larijani B, Adibi H, Javadi E, Sedaghat M, Pajouhi M, et al. Vitamin D deficiency and causative factors in the population of Tehran. BMC Public Health. 2004; 4:38. doi: 10.1186/1471-2458-438. PMCID: PMC517720.

20) Heshmat R, Mohammad K, Majdzadeh SR, Forouzanfar MH, Bahrami A, Ranjbar GH, et al. Vitamin D Deficiency in Iran: A Multi-center Study among Different Urban Areas. Iran J Public Health. 2008; suppl1: 72-8. PMCID: PMC3481630.

21) Holick, M, Chen TC. Vitamin D deficiency: a worldwide problem with health consequences. Am J Clin Nutr. 2008 Apr;87(4):1080S-6S. PMID: 18400738.

22) Moradzadeh K, Larijani MB, Keshtkar AA, Hosein-nejad A, Rajabian R, Nabipour E, et al. Normal levels of vitamin D and vitamin D deficiency in Iran. Scientific Journal of Kurdistan University of Medical Sciences. 2005;10:33-43.

23) Lindsay R, Meunier PJ: Osteoporosis: Review of the evidence for prevention, diagnosis and treatment and cost-effectiveness analysis. Osteoporosis International. 1998; 8(Suppl. 4):3-10.

24) Report of a WHO Study Group. Assessment of fracture risk and its application to screening for postmenopausal osteoporosis. Report of a WHO Study Group. World Health Organ Tech Rep Ser. 1994;843:1-129. PMID: 7941614.

25) Landin-Wilhelmsen K, Wilhelmsen L, Wilske J, Lappas G, Rosén T, Lindstedt G, et al. Sunlight increases serum 25(OH) vitamin D concentration whereas 1,25(OH)2D3 is unaffected. Results from a general population study in Göteborg, Sweden (The WHO MONICA Project). Eur J Clin Nutr. 1995 Jun;49(6):400-7. PMID: 7656883.

26) Chapuy MC, Preziosi P, Maamer M, Arnaud S, Galan P, Hercberg S, et al. Prevalence of vitamin D insufficiency in an adult normal population. Osteoporos Int. 1997;7(5):439-43. PMID: 9425501.

27) Burnand B, Sloutskis D, Gianoli F, Cornuz J, Rickenbach M, Paccaud F, et al. Serum 25-hydroxyvitamin D: distribution and determinants in the Swiss population. Am J Clin Nutr. 1992;56(3):537-42. PMID: 1503066 . 